\title{
Prevalence and Associated Factors of Anemia among Pregnant Women Receiving Antenatal Care (ANC) at Fatima Hospital in Jashore, Bangladesh: A Cross-Sectional Study
}

\author{
Suzon Ahmed ${ }^{\circledR}$, Md. Abdullah Al Mamun ${ }^{\circledR}$, Niaz Mahmud ${ }^{\circledR}$, Nisat Farzana, \\ Mosammat Sadia Akther Sathi, Biplob Kumar Biswas, Amit Datta, Tanvir Ahmad*
}

Department of Nutrition and Food Technology, Faculty of Applied Science and Technology, Jashore University of Science and Technology, Jashore, Bangladesh

Email: ^fmtanvir@gmail.com

How to cite this paper: Ahmed, S., Al Mamun, Md.A., Mahmud, N., Farzana, N., Sathi, M.S.A., Biswas, B.K., Datta, A. and Ahmad, T. (2019) Prevalence and Associated Factors of Anemia among Pregnant Women Receiving Antenatal Care (ANC) at Fatima Hospital in Jashore, Bangladesh: A Cross-Sectional Study. Food and Nutrition Sciences, 10, 1056-1071.

https://doi.org/10.4236/fns.2019.109076

Received: August 7, 2019

Accepted: September 2, 2019

Published: September 5, 2019

Copyright $\odot 2019$ by author(s) and Scientific Research Publishing Inc. This work is licensed under the Creative Commons Attribution International License (CC BY 4.0).

http://creativecommons.org/licenses/by/4.0/

\begin{abstract}
Since anemia is one of the most skyrocketed public health problems worldwide, an investigation has thus been conducted to assess the prevalence and associated factors of anemia among the pregnant women receiving antenatal care (ANC) at Fatima Hospital in Jashore, Bangladesh. Facility-based crosssectional study was carried out among 384 pregnant women at Fatima hospital, Bangladesh from February to April, 2019. Data were obtained using a structured questionnaire and participant's current medical record card. Binary logistic regression analysis was used to identify factors associated with anemia and a P-value $<0.05$ was considered as statistically significance. The overall prevalence of anemia among pregnant women was 58.9\% (226/384). Out of 226 anemic pregnant mothers, 36.3\% (82/226) were mildly anemic, $62.4 \%(141 / 226)$ were moderately anemic and $1.3 \%$ (3/384) was severely anemic. Binary logistic regression analysis revealed that the following variables were significantly associated with anemia: Monthly family income $(11,000-20,000$ Taka) [AOR $(95 \% \mathrm{CI})=0.45(0.21-0.98)]$, Family size (joint) [AOR $(95 \% \mathrm{CI})=1.59(1.03-2.45)]$, Gestational age (third trimester) [AOR $(95 \% \mathrm{CI})=2.18(1.40-3.40)]$, birth spacing < 2 years $[$ AOR $(95 \% \mathrm{CI})$ $=2.87(1.51-5.44)]$, Excessive blood loss during previous surgery (Yes) [AOR $(95 \% \mathrm{CI})=2.08(1.14-4.17)]$, Food group eaten 24 hours $(1-4$ groups) [AOR $(95 \% \mathrm{CI})=3.43(1.84-6.39)]$, Breakfast regularly (No) [AOR $(95 \% \mathrm{CI})=3.64(1.36-9.75)]$. The results obtained showed that the prevalence of anemia among pregnant women is severe at Fatima Hospital in Jashore, Bangladesh.
\end{abstract}




\section{Keywords}

Anemia, Antenatal Care (ANC), Socio-Demographic Characteristics, Maternal Characteristics, Dietary Characteristics, Nutritional Characteristics

\section{Introduction}

Anemia is a pathological condition arises when the concentration of hemoglobin $(\mathrm{Hb})$ or hematocrit (HCT) or RBC (red blood cells) count is lower than the recommended normal range level rendering the reduction in the oxygen carrying capacity of red blood cells to tissues while affecting almost all age group of people, frequently pregnant women [1]-[8]. Anemia during pregnancy is a significant public health problem in low-income countries (56\%) and developed countries (18\%) [2]-[9]. Census and other exploratory studies estimated that anemia currently affecting 1.62 billion people worldwide and among those 56 million pregnant women were found anemic while contributing more than 115,000 maternal and 591,000 postnatal deaths globally every year [6] [10] [11] [12] [13]. Usually, Anemia during pregnancy is defined when the Hemoglobin $(\mathrm{Hb})$ concentration level is $<11 \mathrm{~g} / \mathrm{dl}$ [14]. However, there is a detailed category definition are available previously proposed by World Health Organization (WHO) [14]. According to World Health Organization (WHO) anemia during pregnancy have been classified as mild (10.0 - $10.9 \mathrm{~g} / \mathrm{dl})$, moderate (7.0 - 9.9 $\mathrm{g} / \mathrm{dl})$ and severe $(<7.0 \mathrm{~g} / \mathrm{dl})$ based on the level of hemoglobin concentration in blood [14] [15] [16] [17] [18]. Anemia has a number of contributing factors including poor nutritional status, poor diet, poor antenatal care service, sociodemographics, genetic, abortions, infectious disease, frequent labor and multi-parity [16]. However, iron deficiency is the cause of $75 \%$ of anemia cases [16]. Another leading cause of anemia is micro and macronutrients deficiency [18] [19]. Insufficient intake and poor bioavailability of iron-rich foods also have significant contribution for the onset of anemia during pregnancy [16]. According to many studies, severity of anemia during pregnancy has been found responsible for poor maternal and fetal outcomes [20] [21] [22] [23]. The most common obstetric problems of anemia during pregnancy include; abortion, prematurity, intrauterine fetal death, neonatal low birth weight, postnatal mortality and morbidity [20]-[27]. In Bangladesh, there were three different surveys previously conducted and estimating the prevalence of anemia among pregnant women and the percentage (\%)prevalence were found as 50\%, 59\% and 63\% [9] [25]. However, to our information there was no other studies have ever been conducted at the area we are investigating regarding the prevalence of anemia during pregnancy. Since information on anemia and its associated factors with maternal anemia is not available in this area so our purpose of this study was to investigate the prevalence and to probe the associated factors of anemia among pregnant women receiving Antenatal Care (ANC) at Fatima Hospital in Jashore, Bangladesh. 


\section{Materials and Methods}

\subsection{Study Design}

A facility-based cross-sectional study.

\subsection{Period and Area}

The study was carried out from $2^{\text {nd }}$ February to $24^{\text {th }}$ April 2019 at Fatima Hospital in Jashore, Bangladesh, a Christian missionary hospital which was established in 1970 and providing high quality services, developing and implementing effective programs particularly for the vulnerable and poor people including pregnant women.

\subsection{Study Population}

The study populations were pregnant women in all trimester who visited at Fatima Hospital for antenatal care. Participants who were pregnant and fulfilled the inclusion criteria were included in the study. Each participant was enrolled only once on their first visit during the study period.

\subsection{Sample Size Determination and Sampling Procedures}

The actual sample size for the study was determined based on the prevalence rate of (50\%) anemia in pregnant women in Bangladesh from the previous study and also to get maximum sample size. The $95 \%$ confidence interval and 5\% marginal error, sample size (n) the formula is shown below was used to determine the sample size. Simple random sampling technique was applied. Individual women who self-reported to the health center were included until 384 sample sizes were obtained [2].

$$
N=\frac{Z^{2} \times P(1-P)}{D^{2}}
$$

where,

$$
\begin{aligned}
& D=\text { Marginal error, } 5 \%, \\
& N=\text { Sample size, } \\
& Z=\text { Confident interval, } 95 \%, \\
& P=\text { Based on } 50 \% \text { prevalence rate on the previous study in Bangladesh [9], } \\
& N=(1.96)^{2} \times 0.5(1-0.50) / 0.0025=384.16 .
\end{aligned}
$$

\subsection{Data Collection Procedures}

A pretested structured questionnaire was used to get socio-demographic characteristics, clinical history, dietary habit and nutritional characteristics of pregnant women. The questionnaire was firstly translated into first language Bengali then retranslated into English. Five trained B.Sc. completed students from department of Nutrition and Food Technology, Jashore University of Science and Technology were hired for the collection and record of the data. The respondents were identified as follows: The interviewers informed the indoor partici- 
pants about the motifs, aim and objectives, risks and benefits of the study, then the interviewers convinced the client to complete the interview process after receiving their routine antenatal care (ANC). Patients interviewed in a private study room and also current medical records were checked. We conducted interview in a safe, secure and confidential environment and then the biological tests result was recorded from the patient obstetric file. Anemia status of pregnant women was classified to mild $(10.0-10.9 \mathrm{~g} / \mathrm{dl})$, moderate $(7.0-9.9 \mathrm{~g} / \mathrm{dl})$ and severe $(<7.0 \mathrm{~g} / \mathrm{dl})$ according to World Health Organization (WHO) [14] [15] [16] [17] [18]. Mid Upper Arm Circumference (MUAC) was also used to determine the nutrition status of pregnant women which was categorized as acute malnutrition or wasting $<21 \mathrm{~cm}$, moderate $21-23 \mathrm{~cm}$ and normal $>23$ $\mathrm{cm}$ [12].

\subsection{Data Processing and Analysis}

Data we reanalyzed using the Statistical Package for the Social Science (SPSS) (version 16.0) Descriptive analysis was employed to calculate frequency and percentage. Frequency tables and charts were used to present the summarized data. Binary logistic regression analysis was employed to identify factors associated with anemia. In every cases $\mathrm{P}$ Value $<0.05$ was considered statistically significance.

\subsection{Inclusion and Exclusion Criteria}

Healthy pregnant women in all trimester, who were consented to provide information was included while excluding participants who were seriously ill and did not want to give their information.

\subsection{Ethical Consideration}

Ethical clearance was obtained from department of Nutrition and Food Technology; Jashore University of Science and Technology. Ethical Review Committee Permission letter was submitted to the Superintendent of Fatima hospital. The aim and objective of the study were explicated clearly to the pregnant women and their families. Their oral permission was taken to conduct this study while preserving the information of each mother under the study confidentially.

\section{Results}

\subsection{Socio-Demographic Characteristics}

A total of 384 pregnant women receiving hospital-based antenatal care (ANC) were including the study. Majority, 144 (37.5\%) of the study participants were found 21 - 25 age group and only 6 (1.6\%) were found 36 or more than 36 years old. More than half of the participants 200 (52.1\%) lived in urban area and rest $184(47.9 \%)$ pregnant women were in rural area. More than three-fourth 296 (77.1\%) pregnant women were Muslim. Among all the participants 122 (31.8\%) pregnant women attended secondary school and $112(29.2 \%)$ completed their 
graduation. All of the pregnant women were married and most of were housewife 309 (80.5\%) (Table 1).

Table 1. Socio-demographic characteristics of the pregnant women $(\mathrm{N}=384)$.

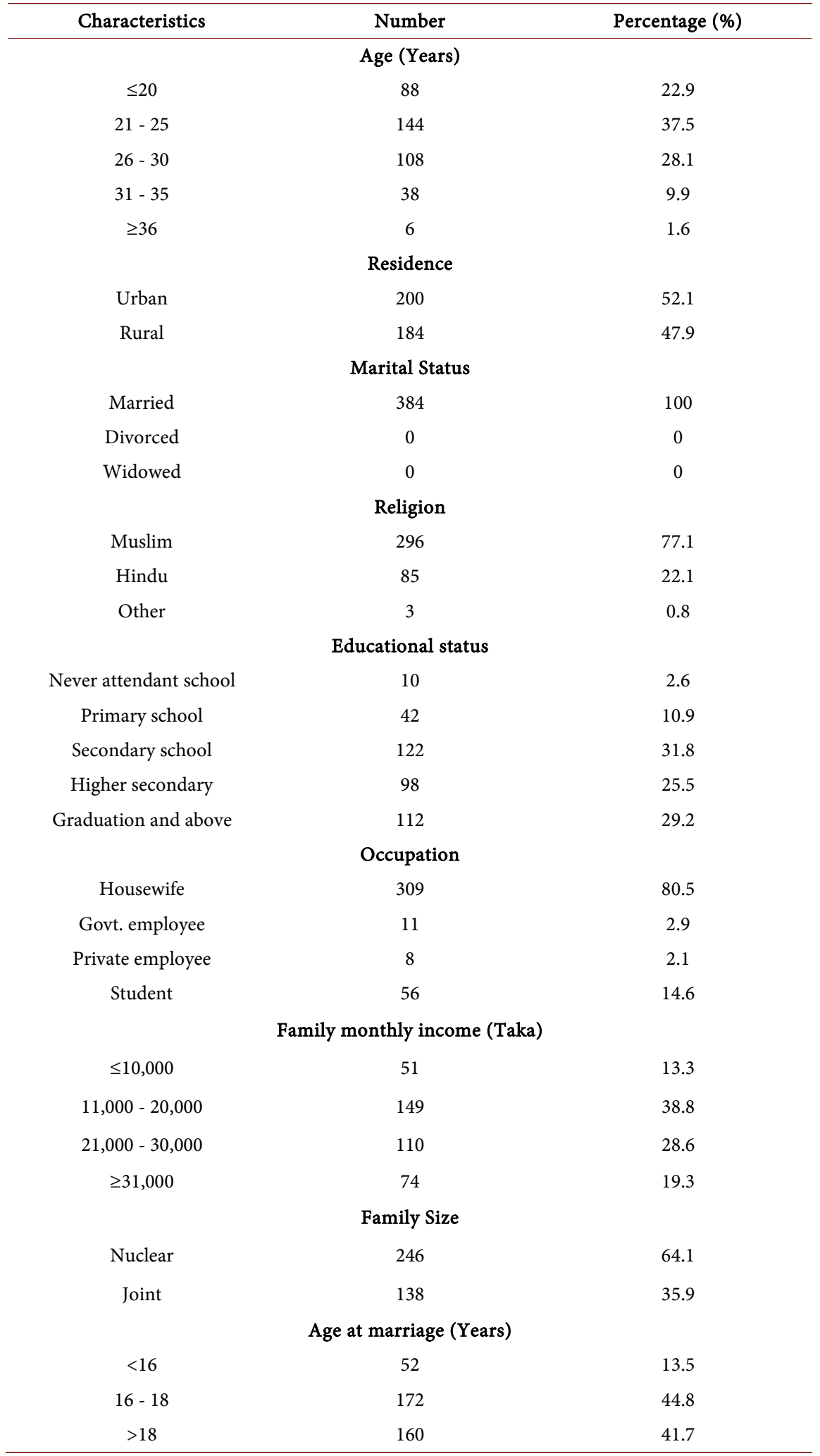




\subsection{Clinical and Maternal Characteristics}

More than half of the pregnant women 221 (57.6\%) were third trimester (gestational age more than 28 weeks), while 127 (33.1\%) were second trimester (gestational age between 13 to 28 weeks) and 36 (9.4\%) were first trimester (gestational age less than 13 weeks). Among all pregnant women 221 (54.9\%) were multi-gravida, more than half of the pregnant women were without child 222 $(57.8 \%)$ and women with one child 139 (36.2\%). More than half of the pregnant women 221 (57.6\%) were attending antenatal more than three times (Table 2).

Table 2. Clinical and maternal characteristics of the study participants.

\begin{tabular}{|c|c|c|}
\hline Characteristics & Number & Percentage (\%) \\
\hline \multicolumn{3}{|c|}{ Gestational age (trimester) } \\
\hline First & 36 & 9.4 \\
\hline Second & 127 & 33.1 \\
\hline Third & 221 & 57.6 \\
\hline \multicolumn{3}{|c|}{ Number of pregnancies } \\
\hline Primigravida & 173 & 45.1 \\
\hline Multigravida & 221 & 54.9 \\
\hline \multicolumn{3}{|c|}{ Number of deliveries } \\
\hline No child & 222 & 57.8 \\
\hline 1 & 139 & 36.2 \\
\hline $2-3$ & 23 & 6.0 \\
\hline 4 and more & 0 & 0 \\
\hline \multicolumn{3}{|c|}{ Level of birth spacing } \\
\hline First pregnancy & 176 & 45.8 \\
\hline$<2$ years & 71 & 18.5 \\
\hline$>2$ years & 137 & 35.7 \\
\hline \multicolumn{3}{|c|}{ Frequency of ANC } \\
\hline First & 76 & 19.8 \\
\hline Second & 87 & 22.7 \\
\hline Third or more & 221 & 57.6 \\
\hline \multicolumn{3}{|c|}{ History of miscarriage } \\
\hline Yes & 100 & 26 \\
\hline No & 284 & 74 \\
\hline \multicolumn{3}{|c|}{ History of previous surgery } \\
\hline Yes & 122 & 31.8 \\
\hline No & 262 & 68.2 \\
\hline \multicolumn{3}{|c|}{ Excessive blood loss during previous surgery } \\
\hline Yes & 45 & 11.7 \\
\hline No & 339 & 88.3 \\
\hline \multicolumn{3}{|c|}{ Current Malaria attack } \\
\hline Yes & 0 & 0 \\
\hline No & 384 & 100 \\
\hline
\end{tabular}




\subsection{Dietary and Nutrition Related Characteristics}

Almost all of the pregnant women $345(89.8 \%)$ consumed meat once or less per week. Everyday fish and green leafy vegetables consumption by participants were 155 (40.4\%), 145 (37.8\%). More than half of the participants 227 (59.1\%) consume fruits once or less per week. Near half of the responded said they ate egg and milk or milk products daily $191(49.7 \%)$ and 188 (49\%). Iron supplement taken by pregnant mother were $260(67.7 \%)$ and iron supplement taken by respondent among 260 participants <30 days 59 (22.7\%), 30 - 60 days 93 (35.8\%), and 60 - 90 days 108 (41.5\%). Near three-fourth of respondent 278 (72.4\%) eaten five to eight group of food daily. Near half of the pregnant women 179 (46.6\%) drink tea or coffee and among 179 participants 86 (48\%) were consume tea or coffee immediately after meal. Majority of the respondents 355 (92.4\%) were daily breakfast taken. Nutritional status of the participants was determined by Mid Upper Arm Circumference (MUAC) and above 384 participants 19 (4.9\%) had MUAC of $<21 \mathrm{~cm}, 46$ (12\%) had MUAC among 21 to 23 $\mathrm{cm}$, and residual $319(83.1 \%)$ had an MUAC within the normal limit $(>23 \mathrm{~cm})$ (Table 3).

\subsection{Prevalence of Anemia}

Among 384 pregnant women who were receiving antenatal care at Fatima Hospital in Jashore $226(58.9 \%)$ were anemic according on their hemoglobin ( $\mathrm{Hb})$ test result and the rest of 158 (41.1\%) did not show anemia (Table 4). Among 226 anemic pregnant mother $82(36.3 \%)$ had mild anemia, $141(62.4 \%)$ had moderate anemia and $3(1.3 \%)$ had severe anemia and (Figure 1).

\subsection{Associated Factors of Anemia among Pregnant Women}

Binary logistic regression analysis was applied to find out the possible associations of anemia and socio-demographic factors: Monthly family income (11,000 - 20,000 Taka) [AOR (95\% CI) $=0.45(0.21-0.98), \mathrm{P}=0.04]$ and family size (joint) $[\mathrm{AOR}(95 \% \mathrm{CI})=1.59(1.03-2.45), \mathrm{P}=0.03]$, Clinical and Maternal

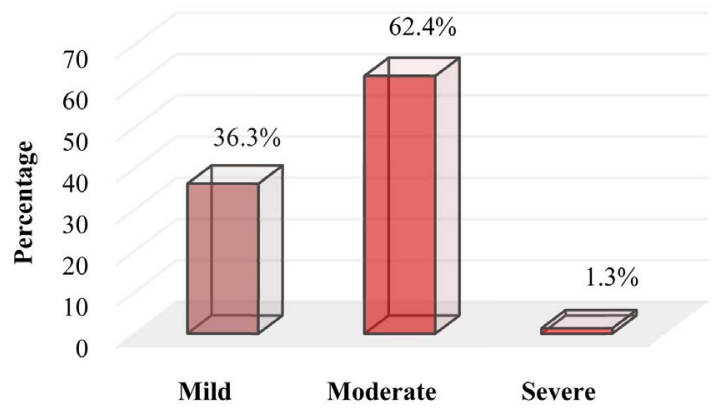

Figure 1. Prevalence of anemia among pregnant women receiving Antenatal Care (ANC) at Fatima Hospital in Jashore, Bangladesh, the percentage were calculated according to the classification recommended by World Health Organization (WHO) of anemia during pregnancy as classified as mild $(10.0-10.9 \mathrm{~g} / \mathrm{dl})$, moderate $(7.0-9.9 \mathrm{~g} / \mathrm{dl})$ and severe $(<7.0 \mathrm{~g} / \mathrm{dl})$ based on the level of hemoglobin concentration in blood [17]. 
Table 3. Dietary and nutritional characteristics of the participants.

\begin{tabular}{|c|c|c|}
\hline Characteristics & Number & Percentage (\%) \\
\hline \multicolumn{3}{|c|}{ Meat consumption } \\
\hline Everyday & 0 & 0 \\
\hline Every two days & 39 & 10.2 \\
\hline Every week or less & 345 & 89.8 \\
\hline \multicolumn{3}{|c|}{ Fish consumption } \\
\hline Everyday & 155 & 40.4 \\
\hline Every two days & 164 & 42.7 \\
\hline Every week or less & 65 & 16.9 \\
\hline \multicolumn{3}{|c|}{ Green leafy vegetables consumption } \\
\hline Everyday & 145 & 37.8 \\
\hline Every two days & 163 & 42.4 \\
\hline Every week or less & 76 & 19.8 \\
\hline \multicolumn{3}{|c|}{ Fruits consumption } \\
\hline Everyday & 43 & 11.2 \\
\hline Every two days & 114 & 29.7 \\
\hline Every week or less & 227 & 59.1 \\
\hline \multicolumn{3}{|c|}{ Egg consumption } \\
\hline Everyday & 191 & 49.7 \\
\hline Every two days & 111 & 28.9 \\
\hline Every week or less & 82 & 21.4 \\
\hline \multicolumn{3}{|c|}{ Milk consumption } \\
\hline Everyday & 188 & 49.0 \\
\hline Every two days & 70 & 18.2 \\
\hline Every week or less & 126 & 32.8 \\
\hline \multicolumn{3}{|c|}{ Iron supplement taken in this antenatal (ANC) period } \\
\hline Yes & 260 & 67.7 \\
\hline No & 124 & 32.3 \\
\hline \multicolumn{3}{|c|}{ Iron supplement taken level } \\
\hline$<30$ days & 59 & 22.7 \\
\hline $31-60$ days & 93 & 35.8 \\
\hline $61-90$ days & 108 & 41.5 \\
\hline \multicolumn{3}{|c|}{ Food group eaten in 24 hours } \\
\hline$>8$ groups & 54 & 14.1 \\
\hline $5-8$ groups & 278 & 72.4 \\
\hline $1-4$ groups & 52 & 13.5 \\
\hline
\end{tabular}




\begin{tabular}{ccc} 
& Drink tea or coffee & \\
Yes & 179 & 46.6 \\
No & 205 & 53.4 \\
Consumption of tea or coffee immediately after meal $\mathbf{n}=179$ & \\
Consume & 86 & 48.0 \\
Not consume & 93 & 52.0 \\
& Daily breakfast taken & \\
Yes & 355 & 92.4 \\
No & 29 & 7.6 \\
MUAC $(\mathrm{cm})$ & & 4.9 \\
$<21$ & 19 & 12.0 \\
$21-23$ & 46 & 83.1 \\
$>23$ & 319 & \\
\hline
\end{tabular}

Table 4. Prevalence of anemia at Fatima hospital in Jashore of the study participants from $2^{\text {nd }}$ February to $24^{\text {th }}$ April, 2019.

\begin{tabular}{ccc}
\hline Characteristics & Number & Percent \\
\hline & Overall prevalence of anemia & \\
Anemia & 226 & 58.9 \\
No anemia & 158 & 41.1 \\
& Severity of anemia $\mathbf{n}=\mathbf{2 2 6}$ & 36.3 \\
Mild & 82 & 62.4 \\
Moderate & 141 & 1.3 \\
\hline
\end{tabular}

characteristics: Gestational age (third trimester) [AOR $(95 \% \mathrm{CI})=2.18(1.40$ $3.40), \mathrm{P}=0.001]$, level of birth spacing $<2$ years $[\mathrm{AOR}(95 \% \mathrm{CI})=2.87(1.51-$ 5.44), $\mathrm{P}=0.001$ ] respectively and blood loss during previous surgery (Yes) [AOR $(95 \% \mathrm{CI})=2.08(1.04-4.17), \mathrm{P}=0.03]$, nutritional characteristics: Food group eaten 24 hours ( 1 - 4 groups) [AOR $(95 \% \mathrm{CI})=3.43(1.84-6.39), \mathrm{P}=0.001$ ] and breakfast regularly $(\mathrm{No})$ [AOR $(95 \% \mathrm{CI})=3.64(1.36-9.75), \mathrm{P}=0.01$ ] were significantly associated with anemia (Table 5).

\section{Discussion}

This study was carried out to assess the prevalence and factors associated of anemia among pregnant women receiving antenatal care (ANC) at Fatima Hospital, Bangladesh. The overall prevalence of anemia among pregnant women in this study was $58.9 \%$. Out of 226 anemic pregnant mothers, 36.3\% (82/226) were mildly anemic, $62.4 \%(141 / 226)$ were moderately anemic and $1.3 \%(3 / 384)$ was severely anemic. According to the World Health Organization classification, the 
Table 5. Associated factors of anemia among pregnant women receiving antenatal care (ANC) at Fatima Hospital in Jashore, $2^{\text {nd }}$ February to $24^{\text {th }}$ April, 2019.

\begin{tabular}{|c|c|c|c|c|}
\hline \multicolumn{5}{|c|}{ Anemia status } \\
\hline Variable & Anemia (\%) & Normal (\%) & $\mathrm{P}$-value & $\operatorname{AOR}(95 \% \mathrm{CI})$ \\
\hline \multicolumn{5}{|c|}{ Age of mothers (Years) } \\
\hline$\leq 20$ & $45(51.1)$ & $43(48.9)$ & & 1 \\
\hline $21-25$ & $83(57.6)$ & $61(42.4)$ & 0.47 & $1.91(0.33-10.98)$ \\
\hline $26-30$ & $69(63.9)$ & $39(36.1)$ & 0.66 & $1.47(0.26-8.29)$ \\
\hline $31-35$ & $25(65.8)$ & $13(34.2)$ & 0.89 & $1.13(0.20-6.46)$ \\
\hline$\geq 36$ & $4(66.7)$ & $2(33.3)$ & 0.97 & $1.04(0.17-6.45)$ \\
\hline \multicolumn{5}{|c|}{ Residence } \\
\hline Urban & $113(56.5)$ & $87(43.5)$ & & 1 \\
\hline Rural & $113(61.4)$ & $71(38.6)$ & 0.33 & $1.23(0.82-1.84)$ \\
\hline \multicolumn{5}{|c|}{ Family monthly income (Taka) } \\
\hline$\leq 10,000$ & $38(74.5)$ & $13(25.5)$ & & 1 \\
\hline $11,000-20,000$ & $83(55.7)$ & $66(44.3)$ & $0.04^{*}$ & $0.45(0.21-0.98)$ \\
\hline $21,000-30,000$ & $63(57.3)$ & $47(42.7)$ & 0.88 & $1.04(0.60-1.83)$ \\
\hline$\geq 31,000$ & $42(56.8)$ & $32(43.2)$ & 0.94 & $0.98(0.54-1.78)$ \\
\hline \multicolumn{5}{|c|}{ Family size } \\
\hline Nuclear & $135(54.9)$ & $111(45.1)$ & & 1 \\
\hline Joint & $91(65.1)$ & $47(34.1)$ & $0.03^{*}$ & $1.59(1.03-2.45)$ \\
\hline \multicolumn{5}{|c|}{ Gestational age (trimester) } \\
\hline First & $25(69.4)$ & $11(30.6)$ & & 1 \\
\hline Second & $58(45.7)$ & $69(54.3)$ & 0.58 & $0.81(0.38-1.73)$ \\
\hline Third & $143(64.7)$ & $78(35.3)$ & $0.001^{\star}$ & $2.18(1.40-3.40)$ \\
\hline \multicolumn{5}{|c|}{ Number of pregnancies } \\
\hline Primigravida & $98(56.6)$ & $75(43.4)$ & & 1 \\
\hline Multigravida & $128(60.7)$ & $83(39.3)$ & 0.42 & $1.18(0.79-1.78)$ \\
\hline \multicolumn{5}{|c|}{ Number of deliveries } \\
\hline No & $128(57.7)$ & $94(42.3)$ & & 1 \\
\hline 1 & $80(57.6)$ & $59(42.4)$ & 0.06 & $2.64(0.95-7.38)$ \\
\hline $2-3$ & $18(78.3)$ & $5(21.7)$ & 0.06 & $2.66(0.93-7.56)$ \\
\hline \multicolumn{5}{|c|}{ Level of birth spacing $N=208$} \\
\hline$>2$ years & $72(52.6)$ & $65(47.4)$ & & 1 \\
\hline$<2$ years & $54(76.1)$ & $17(23.9)$ & $0.001^{\star}$ & $2.87(1.51-5.44)$ \\
\hline \multicolumn{5}{|c|}{ Frequency of ANC } \\
\hline First & $47(61.8)$ & $29(38.2)$ & & 1 \\
\hline Second & $48(55.2)$ & $39(44.8)$ & 0.69 & $0.90(0.53-1.53)$ \\
\hline Third or more & $131(59.3)$ & $90(40.7)$ & 0.51 & $1.18(0.72-1.95)$ \\
\hline
\end{tabular}




\section{Continued}

\begin{tabular}{|c|c|c|c|c|}
\hline \multicolumn{5}{|c|}{ Excessive blood loss during previous surgery } \\
\hline Yes & $33(73.3)$ & $12(26.7)$ & $0.039^{*}$ & $2.08(1.04-4.17)$ \\
\hline No & $193(56.9)$ & $146(43.1)$ & & 1 \\
\hline \multicolumn{5}{|c|}{ Iron supplement taken in this antenatal (ANC) period } \\
\hline Yes & $148(56.9)$ & $112(43.1)$ & & 1 \\
\hline No & $78(62.9)$ & $46(37.1)$ & 0.26 & $1.28(0.83-1.99)$ \\
\hline \multicolumn{5}{|c|}{ Food group eaten in 24 hours } \\
\hline$>8$ groups & $17(31.5)$ & $37(68.5)$ & & 1 \\
\hline 5 - 8 groups & $170(61.2)$ & $108(38.8)$ & 0.06 & $0.53(0.27-1.03)$ \\
\hline $1-4$ groups & $39(75.0)$ & $13(25.0)$ & $0.001^{*}$ & $3.43(1.84-6.39)$ \\
\hline \multicolumn{5}{|c|}{$\operatorname{MUAC}(\mathrm{cm})$} \\
\hline$<21$ & $10(52.6)$ & $9(47.4)$ & & 1 \\
\hline $21-23$ & $30(65.2)$ & $16(34.8)$ & 0.63 & $1.26(0.50-3.18)$ \\
\hline$>23$ & $186(58.3)$ & $133(41.7)$ & 0.37 & $0.75(0.39-1.42)$ \\
\hline \multicolumn{5}{|c|}{ Breakfast regularly } \\
\hline Yes & $202(56.9)$ & $153(43.9)$ & & 1 \\
\hline No & $24(82.8)$ & $5(17.2)$ & $0.01^{*}$ & $3.64(1.36-9.75)$ \\
\hline
\end{tabular}

$1=$ Reference; AOR $=$ Adjuster Odds Ratio; $\mathrm{CI}=$ Confidential Interval; ${ }^{\star} \mathrm{P}<0.05$ statistically significant association for the Adjusted Odds Ratio.

prevalence of anemia among pregnant women in this study was a severe public health problem [17] [28] [29]. The prevalence determined in this study area was comparable with other studies reported in different countries: Bangladesh (59\%), Bhutan (59\%), and Sri Lanka (60\%) [25], China (58.6\%) [18], Malaysia (57.4\%) [27]; higher than Republic in Korea (30.2\%), South Africa (19.7\%) [15], in rural area of Southern Ethiopia (29\%); and lower than India (87.2\%), Pakistan (90.5\%) [27] and Nepal (73\%) [9]. Socio-demographic factors are associated with anemia among pregnant women [22]. The current study has showed that only monthly family income (in Bangladeshi Taka) and family size were significantly associated with anemia. Participants who had family monthly income (Taka) (11,000 to 20,000 Bangladeshi Taka) [AOR (95\% CI) $=0.45(0.21-0.98)$, $\mathrm{P}=0.04]$ were less likely to be anemic as compared to those with low monthly family income (Taka) $(<10,000$ Bangladeshi Taka). The similar findings had also been reported in another study conducted in China [1], Southern Ethiopia [6], Dhaka, Bangladesh [25], Arba Minch, Ethiopia [26], Northwest Ethiopia [30], and Addis Ababa, Ethiopia [31]. Numerous studies have transpired that low household monthly income disturbs the household food purchasing capacity while affecting the household food security. In addition, people living in poor households are found with diminished dietary intake and high risk of nutritional deficiencies [30] [31]. The present study revealed that, the family size was also significantly associated with anemia. Participants with family size (joint) [AOR 
$(95 \% \mathrm{CI})=1.59(1.03-2.45), \mathrm{P}=0.03$ ] were 1.59 times higher risk of anemia than family size nuclear. This finding is similar with a study conducted at Tikur Anbessa Hospital, Ethiopia [32], JigJiga, Eastern Ethiopia [13], and Southern Ethiopia [31]. The large family size is related to anemia among pregnant women could be due to food insecurity [31]. Clinical and maternal characteristics are known important determinants of anemia [32]. The current study showed that gestational age (trimester) was a significantly associated with anemia among pregnant women and the risk of developing anemia increases with the gestational age. The risk of developing anemia was higher in the third trimester compared than the first and second trimester. The current study showed that, the prevalence of anemia was 2.18 times higher at third trimester [AOR (95\% CI) $=2.18$ (1.40 - 3.40), $\mathrm{P}=0.001]$ than first trimester. The study finding was well-matched with other studies conducted at Adigrat General Hospital, Northern Ethiopia [5], Southern Ethiopia [6], JigJiga, Eastern Ethiopia [13], Addis Ababa, Ethiopia [27], Southern Ethiopia [31], and Tikur Anbessa Specialized Hospital, Addis Ababa Ethiopia [32]. Pregnant women's birth interval having less than two years [AOR $(95 \% \mathrm{CI})=2.87(1.51-5.44), \mathrm{P}=0.001$ ] were 2.87 times more likely to be anemic compared to those with birth interval more than two years. This study finding is also found similar with other studies conducted in at Northern Ethiopia [4], Addis Ababa Ethiopia [32], and Arba Minch Town, Ethiopia [26]. The birth interval less than two years might be associated with a decreased iron store of women due to increase the incidence of anemia in pregnancy. The present study also showed that, history of blood loses (yes) [AOR (95\% CI) $=2.08(1.04$ 4.17), $\mathrm{P}=0.03$ ] was statistically significant association with anemia. Findings were similar with the study conducted at Southern Ethiopia [2], Northern Ethiopia [5], Southeast Ethiopia [7], Tigray region, northern Ethiopia [21], and Addis Ababa Ethiopia [32]. Food group eaten 24 hours (1 - 4 groups) [AOR (95\% $\mathrm{CI})=3.43$ (1.84 - 6.39), $\mathrm{P}=0.001] 3.43$ times were more anemic than who are eaten $>8$ food groups. Breakfast regularly (No) $[$ AOR $(95 \% \mathrm{CI})=3.64(1.36$ 9.75), $\mathrm{P}=0.01] 3.64$ times were more anemic than who were breakfast regularly. The result was reliable with studies conducted at Northern Ethiopia [10], Mekelle Town [12], and Tigray region, northern Ethiopia [21]. In those studies participants were showed more anemic who were meal frequency less than two or three times. However, the current study did not show any statistically significant association between anemia and occupation (housewives), mother's education level, and iron supplement but previously statistically significant association s was reported in different studies.

\section{Conclusions}

More than half (58.9\%) the pregnant mothers were anemic among those participants which are a severe public health problem. In the current study we found a high prevalence of anemia and the majority of them were showed the moderate type anemia (Hb level: 7 - $9.9 \mathrm{~g} / \mathrm{dl}$ ). Monthly family income, family size, gestational age, level of birth spacing, excessive blood loss in the previous surgery, 
food group eaten 24 hours and breakfast regularly were a significant association of anemia. Therefore, it is recommended to enhance the socio-economic status, diversifying food intake and increasing meal frequency of pregnant women. Moreover, using family planning methods and maternal health education is highly recommended to reduce anemia during pregnancy.

\section{Limitations}

The study was institutional based study. Further study should be conducted based on a community level to make this finding stronger. We did not consider other factors like parasitic infections which is an important factor of anemia. We were therefore not able to determine their contribution to anemia in our study population. Being a cross-sectional study, therefore, we could not identify the cause and effect relationship.

\section{Acknowledgements}

We would like to thank all the pregnant women attending antenatal care who participated in this study, our heartiest gratitude to all the doctors and stuffs from the Infant \& Maternal department of Fatima Hospital for their great patience and full cooperation during the data collection.

\section{Conflicts of Interest}

The authors declare no conflict of interest.

\section{References}

[1] Lin, L., Wei, Y., Zhu, W., et al. (2018) Prevalence, Risk Factors and Associated Adverse Pregnancy Outcomes of Anaemia in Chinese Pregnant Women: A Multicentre Retrospective Study. BMC Pregnancy and Childbirth, 18, Article No. 111. https://doi.org/10.1186/s12884-018-1739-8

[2] Getahun, W., Belachew, T. and Wolide, A.D. (2017) Burden and Associated Factors of Anemia among Pregnant Women Attending Antenatal Care in Southern Ethiopia: Cross Sectional Study. BMC Research Notes, 10, Article No. 276. https://doi.org/10.1186/s13104-017-2605-x

[3] Mengist, H.M., Zewdie, O. and Belew, A. (2017) Intestinal Helminthic Infection and Anemia among Pregnant Women Attending Ante-Natal Care (ANC) in East Wollega, Oromia. BMC Research Notes, 10, Article No. 440. https://doi.org/10.1186/s13104-017-2770-y

[4] Kebede, A., Gerensea, H., Amare, F., Tesfay, Y. and Teklay, G. (2018) The Magnitude of Anemia and Associated Factors among Pregnant Women Attending Public Institutions of Shire Town, Shire, Tigray. BMC Research Notes, 11, Article No. 595. https://doi.org/10.1186/s13104-018-3706-X

[5] Berhe, B., Mardu, F., Legese, H., Gebrewahd, A., Gebremariam, G. and Tesfay, K. (2019) Prevalence of Anemia and Associated Factors among Pregnant Women in Adigrat General. BMC Research Notes, 12, Article No. 310. https://doi.org/10.1186/s13104-019-4347-4

[6] Lebso, M., Anato, A. and Loha, E. (2017) Prevalence of Anemia and Associated Factors among Pregnant Women in Southern Ethiopia: A Community Based Cross- 
Sectional Study. PLOS ONE, 12, e0188783.

https://doi.org/10.1371/journal.pone.0188783

[7] Filagot, E. and Yaregal, L. (2014) Anemia among Pregnant Women in Southeast Ethiopia: Prevalence, Severity and Associated Risk Factors. BMC Research Notes, 7, Article No. 771 http://www.biomedcentral.com/1756-0500/7/771 https://doi.org/10.1186/1756-0500-7-771

[8] Mihiretie, H., et al. (2015) Magnitude of Anemia and Associated Factors among Pregnant Women Attending Antenatal Care in Nekemte Health Center, Nekemte, Ethiopia. Journal of Medical Microbiology and Diagnosis, 4, 197. https://doi.org/10.4172/2161-0703.1000197

[9] Hyder, S.Z., Persson, L.-Å., Chowdhury, M., Lönnerdal, B. and Ekström, E.-C. (2004) Anaemia and Iron Deficiency during Pregnancy in Rural Bangladesh. Public Health Nutrition, 7, 1065-1070. https://doi.org/10.1079/PHN2004645

[10] Gebre, A. and Mulugeta, A. (2015) Prevalence of Anemia and Associated Factors among Pregnant Women in North Western Zone of Tigray, Northern Ethiopia: A Cross-Sectional Study. Journal of Nutrition and Metabolism, 2015, Article ID: 165430. https://doi.org/10.1155/2015/165430

[11] Ndukwu, G.U. and Dienye, P.O. (2012) Prevalence and Socio-Demographic Factors Associated with Anaemia in Pregnancy in a Primary Health Centre in Rivers State, Nigeria. African Journal of Primary Health Care \& Family Medicine, 4, a328. https://doi.org/10.4102/phcfm.v4i1.328

[12] Abriha, A., Yesuf, M.E. and Wassie, M.M. (2014) Prevalence and Associated Factors of Anemia among Pregnant Women of Mekelle Town: A Cross Sectional Study. BMC Research Notes, 7, Article No. 888. https://doi.org/10.1186/1756-0500-7-888

[13] Gebretsadik Bereka, S., Gudeta, A.N., Abate Reta, M. and Assefa Ayana, L. (2017) Prevalence and Associated Risk Factors of Anemia among Pregnant Women in Rural Part of JigJiga City, Eastern Ethiopia: A Cross Sectional Study. Journal of Pregnancy and Child Health, 4, 337. https://doi.org/10.4172/2376-127X.1000337

[14] Obai, G., Odongo, P. and Wanyama, R. (2016) Prevalence of Anaemia and Associated Risk Factors among Pregnant Women Attending Antenatal Care in Gulu and Hoima Regional Hospitals in Uganda: A Cross Sectional Study. BMC Pregnancy Childbirth, 16, Article No. 76. https://doi.org/10.1186/s12884-016-0865-4

[15] Asrie, F. (2017) Prevalence of Anemia and Its Associated Factors among Pregnant Women Receiving Antenatal Care at Aymiba Health Center, Northwest Ethiopia. Journal of Blood Medicine, 8, 35-40. https://doi.org/10.2147/JBM.S134932

[16] Shams, S., Ahmad, Z. and Wadood, A. (2018) Prevalence of Iron Deficiency Anemia in Pregnant Women of District Mardan, Pakistan. Journal of Pregnancy and Child Health, 4, 356. https://doi.org/10.4172/2376-127X.1000356

[17] Okube, O.T., Mirie, W., Odhiambo, E., Sabina, W. and Habtu, M. (2016) Prevalence and Factors Associated with Anaemia among Pregnant Women Attending Antenatal Clinic in the Second and Third Trimesters at Pumwani Maternity Hospital, Kenya. Open Journal of Obstetrics and Gynecology, 6, 16-27. https://doi.org/10.4236/ojog.2016.61003

[18] Alem, M., Enawgaw, B., Gelaw, A., Kenaw, T., Seid, M. and Olkeba, Y. (2013) Prevalence of Anemia and Associated Risk Factors among Pregnant Women Attending Antenatal Care in Azezo Health Center Gondar Town, Northwest Ethiopia. Journal of Interdisciplinary Histopathology, 1, 137-144. https://doi.org/10.5455/jihp.20130122042052

[19] Hameed, H., Hameed, A., Bashir, S., Akram, S., Arshad, M. and Afzal, R. (2018) 
Study of Prevalence of Anaemia among Pregnant Women and Its Correlation with Different Risk Factors. Drug Designing, 7, 158. https://doi.org/10.4172/2169-0138.1000158

[20] Adam, I., Ibrahim, Y. and Elhardello, O. (2018) Prevalence, Types and Determinants of Anemia among Pregnant Women in Sudan: A Systematic Review and Meta-Analysis. BMC Hematology, 18, Article No. 31. https://doi.org/10.1186/s12878-018-0124-1

[21] Grum, T., Brhane, E., Hintsa, S. and Kahsay, G. (2018) Magnitude and Factors Associated with Anemia among Pregnant Women Attending Antenatal Care in Public Health Centers in Central Zone of Tigray Region, Northern Ethiopia: A Cross Sectional Study. BMC Pregnancy Childbirth, 18, Article No. 433. https://doi.org/10.1186/s12884-018-2063-z

[22] Lelissa, D. (2015) Prevalence of Anemia among Women Receiving Antenatal Care at Boditii Health Center, Southern Ethiopia. Clinical Medicine \& Research, 4, 79-86. https://doi.org/10.11648/j.cmr.20150403.14

[23] Anlaakuu, P. and Anto, F. (2017) Anaemia in Pregnancy and Associated Factors: A Cross Sectional Study of Antenatal Attendants at the Sunyani Municipal Hospital, Ghana. BMC Research Notes, 10, Article No. 402. https://doi.org/10.1186/s13104-017-2742-2

[24] Bishwajit, G., Yaya, S., Tang, S., et al. (2016) Association of Living Arrangement Conditions and Socioeconomic Differentials with Anemia Status among Women in Rural Bangladesh. BioMed Research International, 2016, Article ID: 4571686. https://doi.org/10.1155/2016/4571686

[25] Chowdhury, H.A., Ahmed, K.R., Jebunessa, F., Akter, J., Hossain, S. and Shahjahan, M. (2015) Factors Associated with Maternal Anaemia among Pregnant Women in Dhaka City. BMC Women's Health, 15, Article No. 77. https://doi.org/10.1186/s12905-015-0234-x

[26] Bekele, A., Tilahun, M. and Mekuria, A. (2016) Prevalence of Anemia and Its Associated Factors among Pregnant Women Attending Antenatal Care in Health Institutions of Arba Minch Town, Gamo Gofa Zone, Ethiopia: A Cross-Sectional Study. Anemia, 2016, Article ID: 1073192. https://doi.org/10.1155/2016/1073192

[27] Gebreweld, A. and Tsegaye, A. (2018) Prevalence and Factors Associated with Anemia among Pregnant Women Attending Antenatal Clinic at St. Paul's Hospital Millennium Medical College, Addis Ababa, Ethiopia. Advances in Hematology, 2018, Article ID: 3942301. https://doi.org/10.1155/2018/3942301

[28] López, A., Cacoub, P., Macdougall, I.C. and Peyrin-Biroulet, L. (2017) Iron Deficiency Anaemia. Paediatrics \& Child Health (United Kingdom), 27, 527-529. https://doi.org/10.1016/j.paed.2017.08.004

[29] Karaoglu, L., Pehlivan, E., Egri, M., et al. (2010) The Prevalence of Nutritional Anemia in Pregnancy in an East Anatolian Province, Turkey. BMC Public Health, 10, 329. https://doi.org/10.1186/1471-2458-10-329

[30] Derso, T., Abera, Z. and Tariku, A. (2017) Magnitude and Associated Factors of Anemia among Pregnant Women in Dera District: A Cross-Sectional Study in Northwest Ethiopia. BMC Research Notes, 10, Article No. 359.

https://doi.org/10.1186/s13104-017-2690-x

[31] Gedefaw, L., Ayele, A., Asres, Y. and Mossie, A. (2015) Anaemia and Associated Factors among Pregnant Women Attending Antenatal Care Clinic in Walayita Sodo Town, Southern Ethiopia. Ethiopian Journal of Health Sciences, 25, 155. https://doi.org/10.4314/ejhs.v25i2.8 
[32] Hailu Jufar, A. (2014) Prevalence of Anemia among Pregnant Women Attending Antenatal Care at Tikur Anbessa Specialized Hospital, Addis Ababa Ethiopia. Journal of Hematology and Thromboembolic Diseases, 2, 125.

https://doi.org/10.4172/2329-8790.1000125 